\title{
No ar cartografias da resistência: construindo novos olhares através da produção audiovisual em um CAPS
}

\author{
On air resistance cartographs: building new views through audiovisual \\ production in a CAPS
}

\author{
Dalmara Fabro de Oliveira; Vilene Moehlecke \\ Universidade do Vale do Rio dos Sinos
}

\section{RESUMO:}

Esse artigo tem como base o memorial descritivo escrito por uma estagiária de Psicologia e sua supervisora, ao narrar a experiência de construção de uma produção audiovisual junto a usuários e trabalhadores de um CAPS, com o objetivo de tornar visíveis as forças de resistência que operam contra a exclusão da loucura. $\mathrm{O}$ trabalho parte das inquietações frente às inúmeras formas pelas quais a loucura foi e ainda é invisibilizada, mostrando que, apesar de tantas conquistas a partir da Reforma Psiquiátrica, ainda persistem formas de enclausuramento. Utilizamos como método de pesquisa a cartografia. A produção audiovisual é tomada como dispositivo estético, com a função de tornar visíveis e dizíveis as forças de resistência neste CAPS. Diferente de uma Psicologia construída na distância e servindo ao ideal de excluir o louco, buscamos um fazer com os sujeitos, superando fronteiras e manicômios mentais.

Palavras-chave: resistência; loucura; produção audiovisual.

\begin{abstract}
:
This article is based on the descriptive memo written by a psychology intern and her supervisor, narrating the experience of building an audiovisual production with users and workers of a CAPS, with the objective of making visible the resistance forces that operate against the exclusion of madness. The work starts from the worries about the innumerable ways in which madness has been and is still invisible, showing that, despite so many achievements from the Psychiatric Reform, there are still forms of enclausuramento. Mapping is used as a research method. Audiovisual production is taken as an aesthetic device, with the function of making visible and tellable the forces of resistance in this CAPS. Unlike a psychology built in the distance and serving the ideal of excluding the crazy, we sought to do with the subjects, overcoming borders and mental asylums.
\end{abstract}

Key-words: resistance; madness; audiovisual production.

DOI: 10.12957/mnemosine.2020.57663 


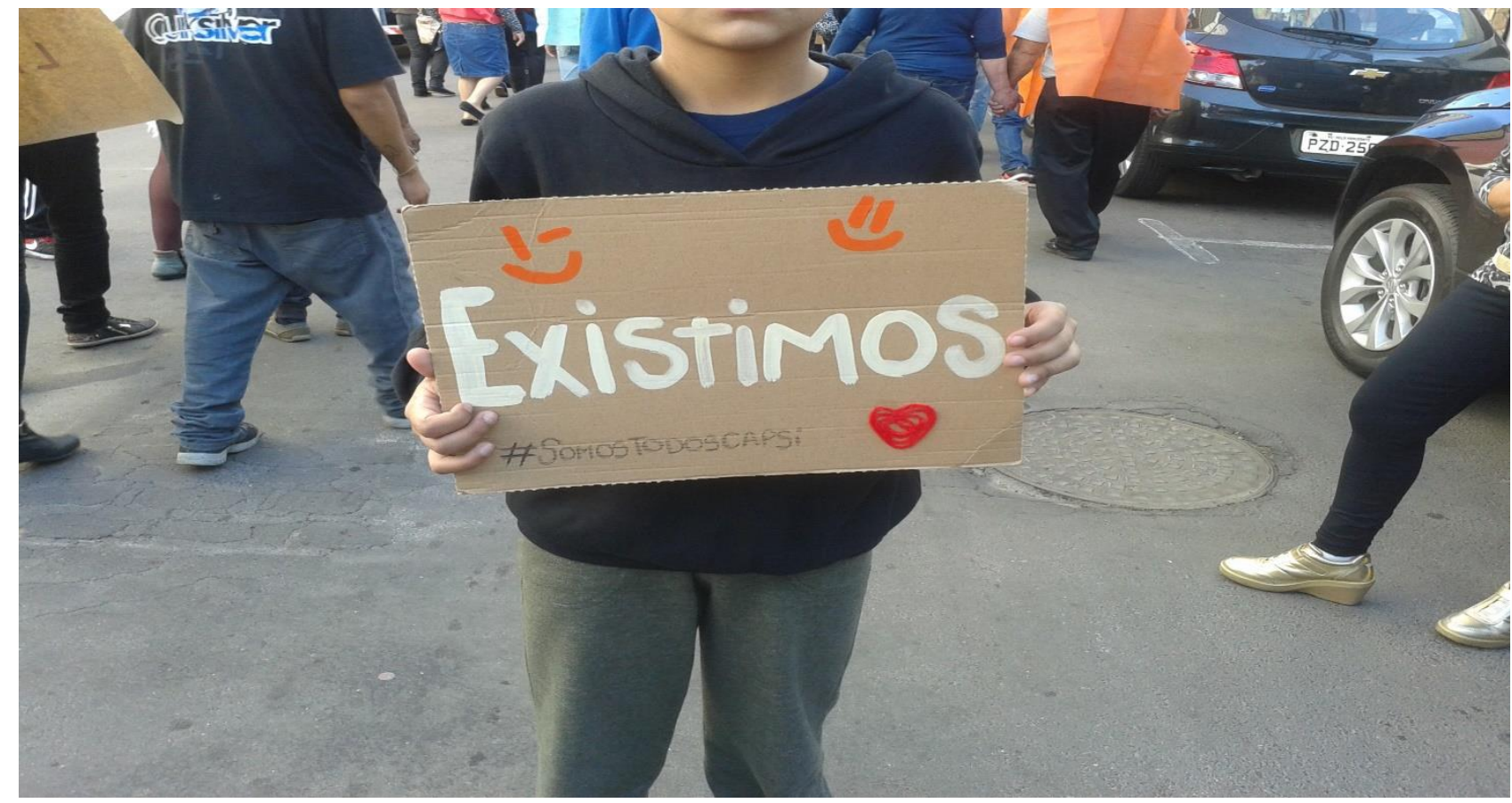

Imagem 1: Fotografia realizada na Caminhada da Luta Antimanicomial do município.

A presente cartografia parte de múltiplos olhares dados à loucura ao longo dos séculos, que deixaram vestígios e marcaram o seu campo hoje. Foucault (1997) e Resende (2001) falam sobre as formas pelas quais, inicialmente em seu estado livre, a loucura passou a incomodar aos olhos da sociedade e precisou ser varrida para dentro dos espaços de confinamento, onde permanece por um longo tempo. Ou seja, a história do louco na Europa do século XVI, e no Brasil do século XIX, mantêm em comum o relato dos inúmeros esforços na tentativa de enclausurar a loucura, invisibilizá-la, excluí-la da paisagem social e do olhar cotidiano.

Entretanto, as denúncias de maus tratos e de condições indignas de existência desencadearam o movimento da reforma psiquiátrica em vários países, como Itália e Brasil, nas décadas de 70 e 90 respectivamente e possibilitaram a abertura dos manicômios, além de um novo olhar sobre os sujeitos loucos. Desse modo, surgem os Centro de Atenção Psicossocial (CAPS) como serviços substitutivos ao modelo hospitalocêntrico e que visam o atendimento no território, sem o afastamento do sujeito da família e da comunidade. Com essa lógica, caracterizam-se pelo ambiente acolhedor e inserido na cidade (AMARANTE, 1995).

Porém, apesar de tantas transformações, o que observamos na pós-reforma não é a exclusão por meio do confinamento, e sim o controle do corpo em sofrimento. Peter Pal Pelbart (1993) fala sobre os manicômios mentais ao se referir às clausuras que, agora, derrubados os muros dos hospitais psiquiátricos, são criadas para manter a loucura longe de nossos olhos. Ele 
retoma o tratamento das sociedades atuais em relação às minorias, ao lhes atribuir identidades, direitos e, na mesma medida, os tornar silenciados, inofensivos, e questiona o que acontecerá com a loucura quando o ideário de uma sociedade sem manicômios por fim se efetivar. Estaria a sociedade instituindo-lhes direitos para, em troca, reduzi-los a corpos passivos e impotentes?

Em outras palavras, no campo da saúde mental, a substituição do modelo hospitalocêntrico, por si só, não implica no fim dos manicômios. Uma mudança na lei não é suficiente para a superação das clausuras e dos desejos de controlar, dominar e oprimir que mantêm os manicômios em atividade, "em nossa 'alma', anônimos, dispersos e prontos para emergir a qualquer momento em defesa da exclusão" (ROMAGNOLI et.al, 2009: 201).

Foucault (1984) fala dessa relação de forças, que reprime e pode dominar a natureza, os instintos, ou mesmo uma classe de indivíduos, chamada de relações de poder. O poder, segundo ele, é um modo de ação de um corpo sobre outro, sobre sua possível ação, que só existe e se exerce em ato, nas relações. Nesse sentido, não opera sobre indivíduos inertes, pois não existem relações de poder sem resistências, sem recusa às imposições e submissões.

Pois se é verdade que no coração das relações de poder e como condição permanente da sua existência, há uma insubmissão e liberdades essencialmente retentoras, não há relação de poder sem resistência, sem escapatória ou fuga, sem retorno eventual; toda a relação de poder implica, portanto, ao menos de forma virtual, uma estratégia de luta, sem que por isso elas se venham a sobrepor, a perder a sua especificidade e finalmente a confundir-se (FOUCAULT, 1984: 14).

Assim, o presente artigo tem como base o memorial descritivo escrito por uma estagiária de Psicologia e sua supervisora, ao narrar a experiência de construção de uma produção audiovisual junto aos usuários e trabalhadores de um CAPS $^{1}$, com o objetivo de tornar visíveis estas forças de resistência que operam contra a exclusão da loucura do social.

Por meio do memorial, esperamos construir uma imagem para aquilo que extravasa os limites, dando passagem à vida que escapa por entre as brechas da contenção, a loucura que não permite ser medicada, estagnada e escondida, mas encontra espaços de fuga para além de um corpo controlado. Por meio do documentário, podemos revelar como se expressam as formas de resistência ao assujeitamento.

Entendemos que, ao falar sobre pessoas e modos de existência invisibilizados na sociedade atual, não podemos simplesmente escrever sobre, é necessário trazê-los à cena, para falarem por eles mesmos. Além disso, por muito tempo, a própria Psicologia serviu aos mecanismos de exclusão, oferecendo apenas o seu olhar, para analisar, classificar e rotular. Na 
procura de cientificidade, tentou separar-se, limitando o espaço de quem estuda - o pesquisador - do objeto a ser estudado. Diferente daquela Psicologia construída na distância, buscamos fazer com os sujeitos e não falar sobre eles. Propomos pensar em uma outra Psicologia, que possa olhá-los em sua complexidade e permita acolher, reparar, notar, ter outras pistas, para além do sujeito e do diagnóstico, como as resistências. O olhar aqui não está distante, para tomar o objeto como não vivo; está tão próximo quanto o olho permite, revelando acima de um psicodiagnóstico que enquadra, oprime e reduz, a vida que dele escapa, a singularidade presente para além do visível.

Romagnoli et.al. (2009: 203) referem que "precisamos lutar contra a produção de hospitais psiquiátricos em miniatura e a imposição de modos de vida enrijecidos e tutelados". Segundo as autoras, essa clínica que visa à superação das fronteiras disciplinares e a não funcionar a serviço da serialização instituída tem como objetivo primeiro a produção e potencialização das resistências, através de uma política de afirmação da vida como uma potência de produção de singularidades. Apostamos na afirmação de que os modos de vida singulares têm o direito de existir e, se existem, de serem olhados pelo social.

Assim, assumimos um fazer em Psicologia disposto a acabar com os muros visíveis e invisíveis que circundam o louco, abrir as portas e os manicômios dentro dos serviços, para a cidade se afetar com ele. Mostrar sua existência, sua história, o que acontece dentro do serviço e quem são as pessoas que fazem parte dele.

Importante sinalizar o lugar das pesquisadoras, enquanto antiga estagiária desse serviço e sua orientadora, ambas engajadas na Luta Antimanicomial. De tal modo, colocamo-nos não apenas como observadoras do processo, e sim como parte integrante do mesmo e buscamos desinstitucionalizar os espaços e os lugares cristalizados: do louco como excluído, do profissional técnico como inacessível e do CAPS como único espaço de circulação da loucura. Assim, retornamos ao serviço, sem a pretensão egoísta e utópica de que as ações produzam grandes mudanças, mas com a possibilidade de olhar para os sujeitos.

Nesse sentido, a presente escrita se compõe a partir de um conjunto de memórias vivenciadas na constituição do documentário, atravessadas por conceitos que auxiliam a problematizar tais construções. Narramos um caminho, um desenrolar de linhas, na concretização de um desejo, produzido durante a vivência do estágio, de tornar visíveis algumas histórias, singularidades e lutas, que expressam os movimentos de resistência presentes nesse espaço. 
O desenrolar da produção elege como método a pesquisa cartográfica. Para os geógrafos, a cartografia acompanha os movimentos de uma determinada paisagem, as mudanças e erosões que a transformam. Isto é, diferente do mapa, uma representação estática, ela se constrói juntamente com os processos de transformações. Enquanto método de pesquisa, a cartografia também tem este intento, o de acompanhar processos; assim, funciona como um mapa móvel onde a realidade é cartografada, ou seja, tomada a partir dos trajetos e dos percursos da própria pesquisa-intervenção. (ROLNIK, 2014; PASSOS, KASTRUP; ESCÓSSIA, 2015).

Ao pensar nessa pesquisa, poderíamos supor que a cartografia teve como finalidade acompanhar o processo de produção cinematográfica. Porém, para além desse processo (linhas duras), são privilegiadas as linhas flexíveis e de fuga, traçando um mapa do que está em vias de acontecer. Mapa de ações micropolíticas e dos processos de produção de subjetividade em curso, acompanhados pelo cartógrafo nos seus movimentos de transformação que esta pesquisaintervenção se propôs a fazer (ROLNIK, 2014; PASSOS, KASTRUP; ESCÓSSIA, 2015).

Produzir um audiovisual através do método cartográfico implica em não ter parâmetros prévios de o que ou quem filmar. Assim, todos os momentos da pesquisa não seguem por meio de um caminho pré-estabelecido, mas se constroem conforme os passos são percorridos. $\mathrm{Ou}$ seja, ocorre uma reversão do sentido tradicional do método. Não existem procedimentos metodológicos predeterminados, informações a serem coletadas, nem mesmo etapas separadas (coleta, análise e discussão de dados), mas a composição de um caminho que vai se desenhando durante o percurso (PASSOS, KASTRUP e ESCÓSSIA, 2015).

A composição cartográfica ocorre desde o convite aos participantes até a filmagem, roteirização e edição, pois visa acompanhar a construção fílmica e aquilo que produz nos envolvidos, sejam eles usuários, trabalhadores, comunidade e as pesquisadoras/cartógrafas em análise de implicação ao longo do processo.

A produção audiovisual tem a pretensão de ser um dispositivo estético, com a função de tornar visíveis e dizíveis alguns jogos de força, além das histórias, dos modos de existir e os próprios sujeitos. O dispositivo, tal como proposto por Deleuze (1990), compõe-se na articulação de pelo menos quatro linhas, a saber: as de visibilidade, as de enunciação, as de força e as de subjetivação. Com isso, não há sentidos a serem revelados; espera-se a sua criação, ao investir na produção de novos olhares, afetos, desejos, sentidos e de linhas.

Escolhemos, então, ao retornar ao serviço, narrar a caminhada, o convite aos participantes, o início das filmagens e aquilo que produz nos envolvidos. Sem dúvida, já vamos 
cartografando movimentos de resistência, cristalizações, relações de poder e enrijecimentos. Nesse processo, o dispositivo, em seu caráter ativo, está em ação e passa a visibilizar essas questões. (BARROS, 1997).

\section{Cartografando olhares}

No início, eram apenas vultos, vozes e sombras que, numa total escuridão, produziam sensações como o choque e, às vezes, até marcas. Nessa escuridão, e com os olhos impossibilitados de enxergar, passamos a usar outros sentidos. Na primeira reunião de equipe: apenas escutar. Os ouvidos atentos tentam imaginar quem são estas pessoas de quem falam, como são seus olhos, seus cabelos.

Quando passamos a enxergar melhor, o que nos toma o olhar, já de início, são as cores. A recepção é colorida, ladeada por duas portas enormes, uma delas dá acesso a um pátio e a outra a uma sala onde ocorrem os grupos. Artesanatos e frases preenchem as paredes e lhes dão um aspecto alegre. Pessoas circulam pelos espaços, um grupo joga cartas, outros conversam ou mesmo fumam no espaço externo, embaixo de uma grande árvore.

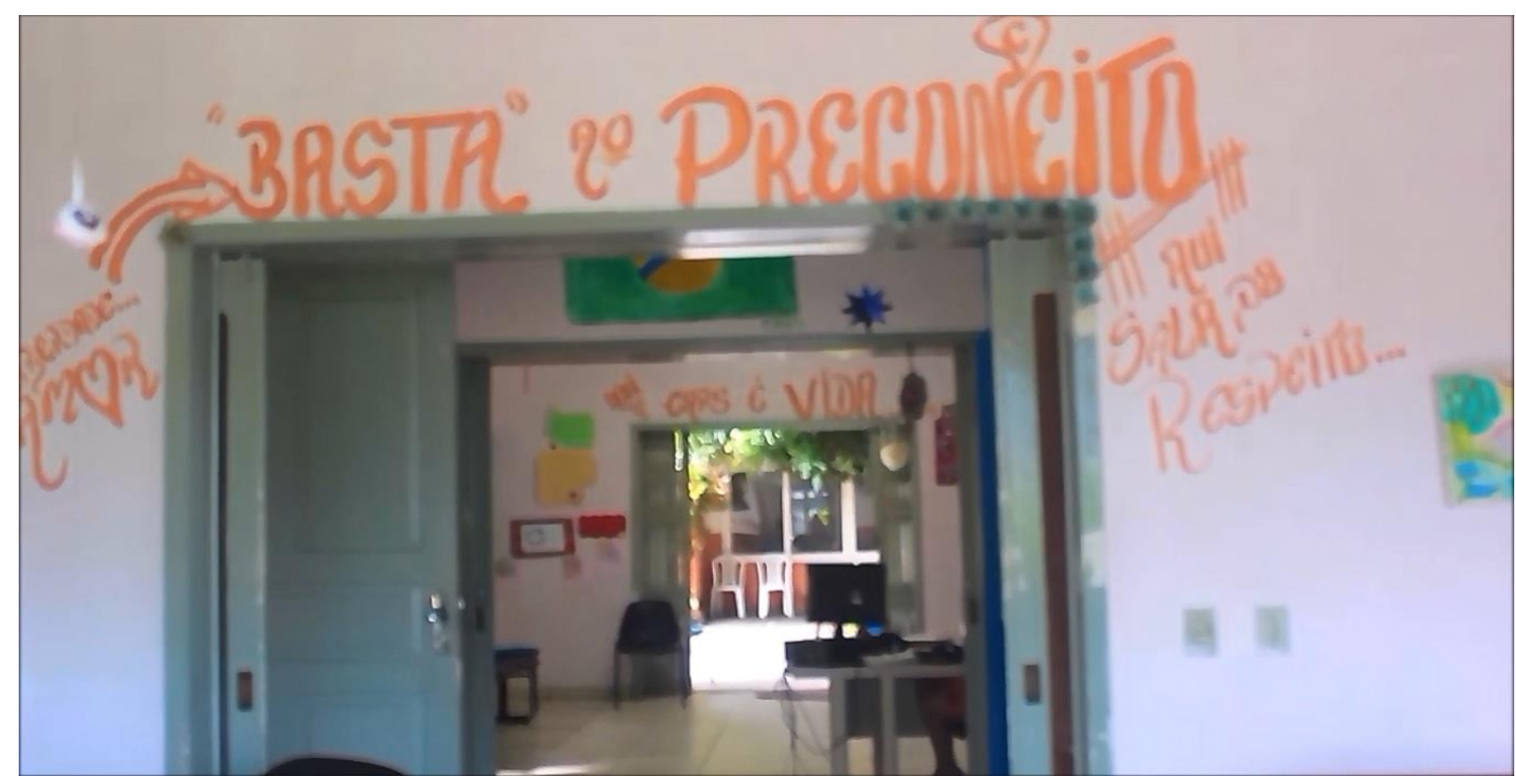

Imagem 2: Imagem retirada da produção audiovisual, mostrando a recepção do CAPS.

Aos poucos, os cochichos e os nomes dos quais ouvimos falar começam a tomar forma e corpo de gente; não só os escutamos, mas podemos vê-los, ouvi-los e até tocá-los e estes 
fragmentos, juntos, fazem suas histórias existirem na nossa. Daí em diante, não é uma escuridão que nos faz encontrá-los, mas uma necessidade. Percorremos os pátios como quem está perdido, sentamos nos bancos a ouvir estórias e, sempre que possível, puxamos um assunto, sabendo que muitos virão. Nesses movimentos, conhecemos singularidades ímpares, que impactam pela potência ao se apresentar.

Pessoas, com histórias de vida únicas e diferentes maneiras de vivenciá-las, muitas vezes cobertas por rótulos, chamados de diagnósticos que, como capas, escondem um ser e o tornam difícil de ser olhado ou, até mesmo, mencionado por elas. Suas narrativas só conseguem ser construídas a partir dos nomes dados em forma de CID (Classificação Internacional de Doenças). A partir dele, trazem suas queixas em relação às dificuldades financeiras, ao sono excessivo, às dificuldades com o sexo, justificam suas perdas e a própria maneira de ser. Porém, algo estranho nesse encantamento inicial quase passa desapercebido, pois muitos ali já estão cegados há muito tempo, tanto que não se reconhecem mais entre si, como se, acostumados com a paisagem, não se permitissem mais olhar.

Usuários invisibilizados, técnicos absortos em seus especialismos e ambos capturados por uma lógica de controle dos corpos, de medicalização da vida, de patologização das existências, onde olhos e ouvidos estão sempre atentos, para que um novo surto não aconteça e, quando ele acontece, é silenciado por mais uma injeção de haloperidol.

Recusamo-nos a permanecer nessa escuridão e percebemos que, apesar dos mecanismos de exclusão e psicopatologização, existem, também, diversos movimentos de resistência, onde a vida, em sua forma singular de expressão, escapa. Ali onde as relações de poder são confrontadas, o que há de mais humano se esvai. Desse modo, colocar os indivíduos numa posição de submissão ao olhar do outro seria desconsiderar esses movimentos.

Assim, a partir de Foucault (1984), passamos a entender o CAPS como um espaço de forças em luta permanente, onde se tenta, a todo o momento, estabelecer um modelo de organização e controle dos corpos loucos, um não-olhar, ou um olhar carregado de despotencialização. Por outro lado, esses corpos lutam o tempo todo para extrapolar, para mostrar-se, sair de suas cadeiras e dançar. São essas inquietações que fazem nascer a cartografia, pois são elas que nos movem e nos fazem voltar a este cenário em busca de existências.

No retorno ao CAPS, por ocasião da pesquisa, deparamo-nos com um serviço ainda mais endurecido. Placas sinalizam os espaços onde é permitida ou não a entrada dos usuários e 
uma nova ferramenta é utilizada para organizar a recepção. O cartaz diz 'Pegue uma senha e aguarde'. Chegamos numa quarta-feira, dia em que o serviço estava sempre cheio e barulhento, dia do Grupo de Música autônomo. Logo nos informam que o grupo terminou, mas o silêncio e o esvaziamento do local já sinalizavam.

No outro dia, o encontro com os participantes do CAPS nos dá um pouco de alegria. Alguém diz ter sonhado com nossa imagem, sorriso, outros perguntam se voltamos, brincadeiras como as do seu Hortênsio ${ }^{2}$ que indaga se ouvimos vozes. Essas vivências trazem muitas lembranças, o seu Hortênsio com sua bicicleta, a Luzineide no GAM (Gestão autônoma da medicação), a Clarinete coreografando e olhando para ver se os colegas faziam certo, a música, o barulho, as cores.

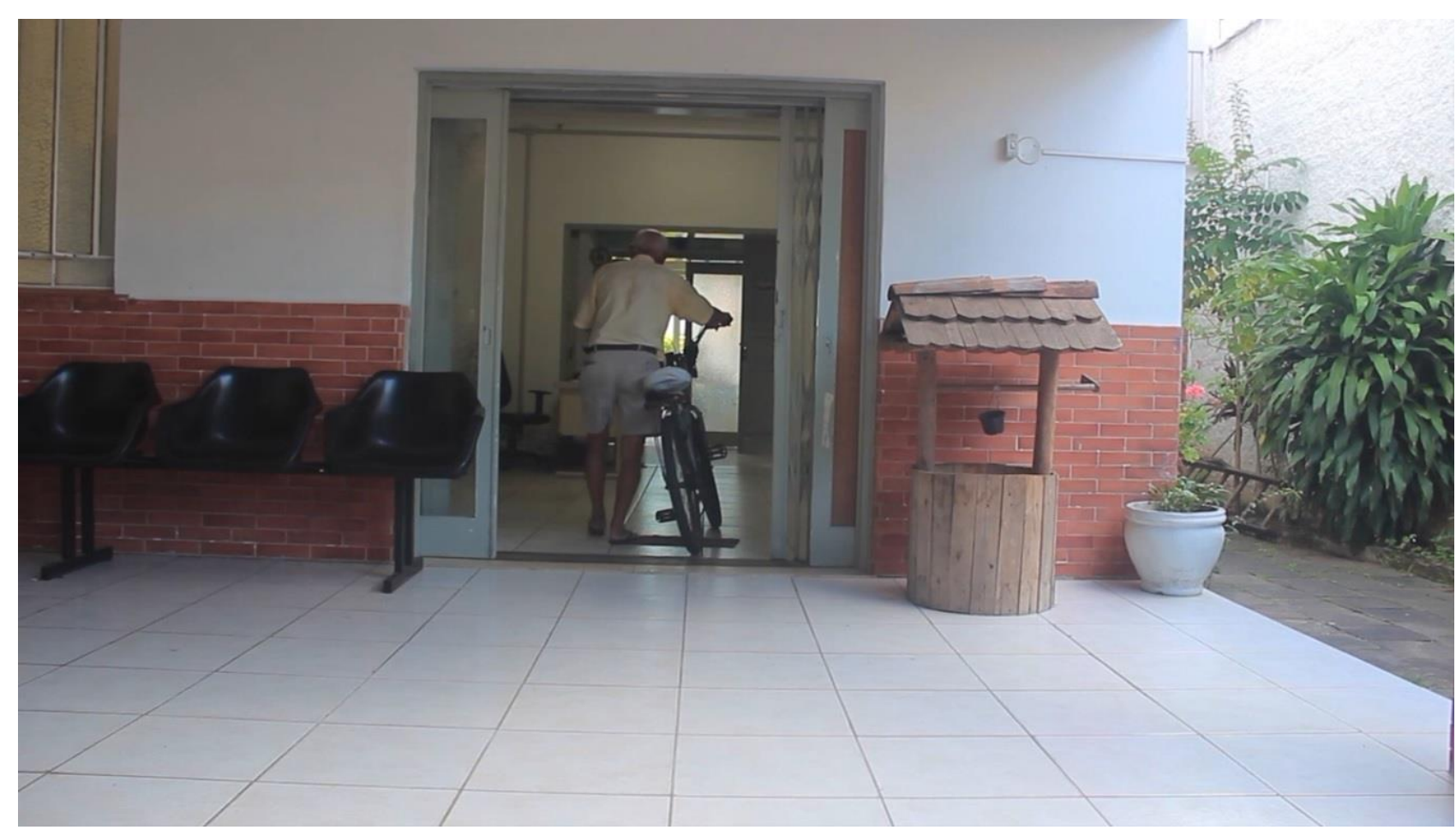

Imagem 3: Imagem retirada da produção audiovisual, Seu Hortênsio com sua bicicleta.

Como estrangeiras no local, nos primeiros dias apenas passeamos, caminhamos e escutamos. No entanto, logo passamos novamente a fazer parte da paisagem, a almoçar com eles, a falar sobre as dificuldades vivenciadas no serviço, a fazer o CAD (Centro de Atenção Diária). Na cartografia, o pesquisador entra em campo, habita o território e explora através da escuta, do olhar, dos odores, gostos e ritmos. Ele participa de vidas, afeta e é afetado por elas e 
pelo que as afeta. Assim, ocorre a dissolução do ponto de vista do observador, ao adotar uma postura indissociável entre pesquisador e pesquisa (PASSOS, KASTRUP e ESCÓSSIA, 2015).

Porém, ao retornar ao CAPS, não o fazemos sozinhas, estamos acompanhadas da câmera com o seu poder de captar, revelar, gravar. Assim como nós, a câmera não permanece neutra, esta nunca fora a pretensão. Seu olho capta muitas coisas e também é captado pelos passantes, pelos atores que acenam, se apresentam, aparecem e, às vezes, sinalizam 'Sorria, você está sendo filmado'.

Apesar de ter planejado encontros-disparadores para discutir expectativas e ideias, o tempo e o caminhar no CAPS não permitem tal intento e, assim, sem abandonar o método, inverte-se o termo em “"hódos-méta', ou seja, um caminhar que traça, no percurso, suas metas" (PASSOS, KASTRUP e ESCÓSSIA, 2015: 17) e construímos no encontro com cada participante o script dessa produção.

O roteiro fica por conta do caminho feito pelas cartógrafas no serviço e acompanha o nosso olhar e de algumas pessoas que caminham conosco. Sem uma ideia prévia do que iria surgir, procuramos entender a construção e o protagonismo como intervenções possíveis de serem produzidas pela pesquisa-filmagem. Isto não significa perder o controle das variáveis, e sim evitar a simples busca por informações, abrindo-se ao encontro. Conforme Rolnik (2014), dar corpo, voz e olhar aos afetos que pedem passagem.

Assim, começamos a percorrer novamente os pátios, sentar aqui e ali com as pessoas e convidá-las a participar da pesquisa. Passamos a vivenciar o serviço e fazer essa história com os sujeitos. Anulamos a distância entre pesquisadoras e participantes do CAPS e pesquisamos com o corpo. Como um cego ao guiar outro e, tateando, acompanha um processo que não conhece de antemão (PASSOS, KASTRUP e ESCÓSSIA, 2015), somos participantes junto aos sujeitos e começamos a pensar os enquadres, as cenas, o roteiro. A maioria das pessoas contatadas aceitam participar das filmagens e fazem isso com muito entusiasmo. Por vezes, demonstram um prazer em mostrar-se, um orgulho em poder contar sua história.

Nesse caminho, encontramos com o 'Grupo Viver', um grupo de artes que resolve construir junto conosco. Conversamos sobre o filmar como um desejo de eternizar o momento, de marcar na memória e preservar aquilo que é útil ao metabolismo mental. Após, com câmeras, celulares e outras máquinas de guardar momentos, eles saem a filmar o serviço e seus espaços. Resolvem ir direto para a sala aonde o acesso é restrito aos profissionais. Ocorre um movimento 
de resistência que, como um catalizador químico, coloca em evidência as relações de poder (FOUCAULT, 1984), pois, mesmo que a placa lhes diga para onde ir, são eles que decidem.

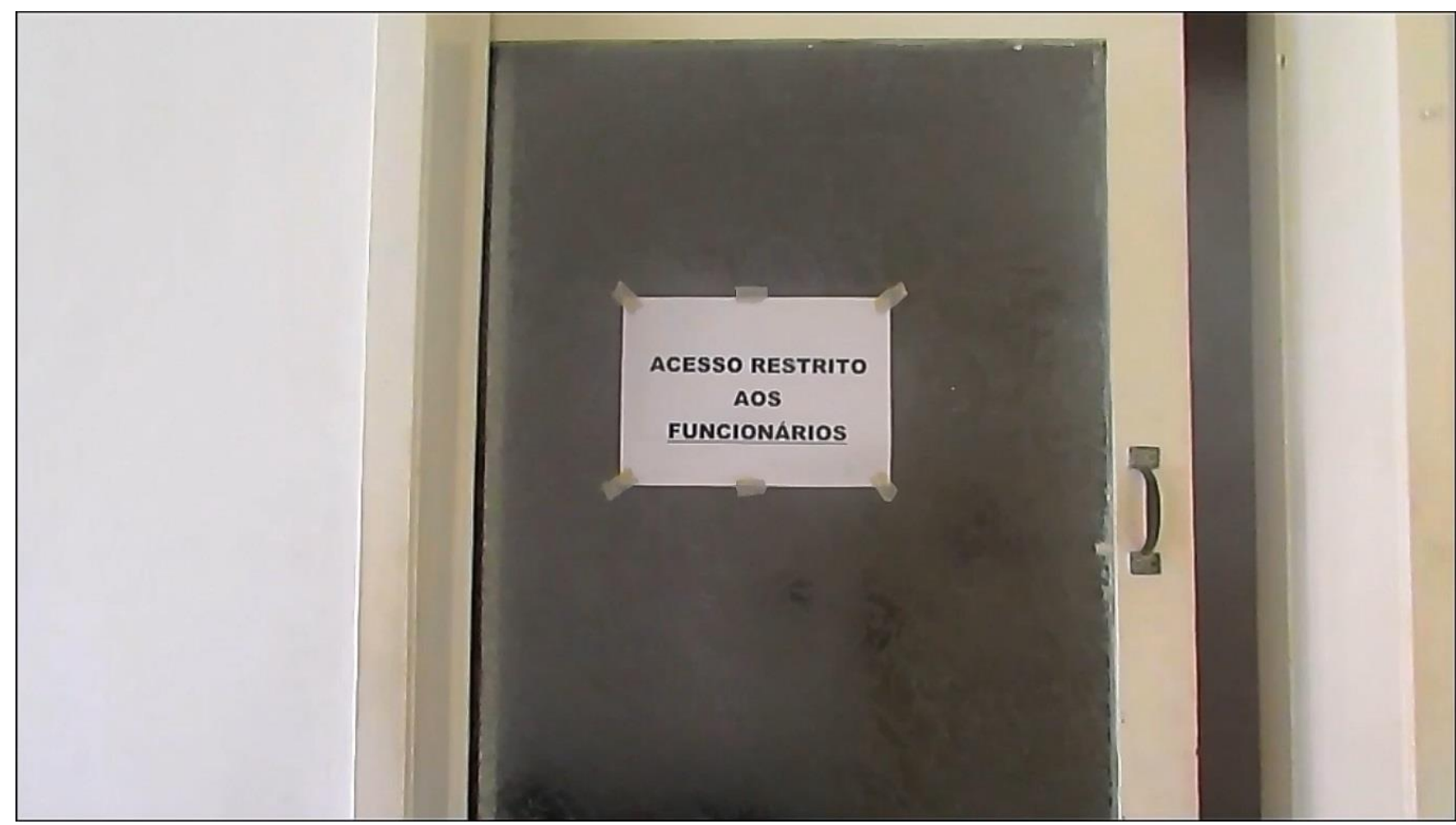

Imagem 4: Imagem retirada da produção audiovisual, mostrando a porta com aviso aos usuários.

Havia também em nós esse mesmo desejo de memória, de nos deparar com uma cena que impactasse, encarnasse e produzisse no expectador algo do que vivemos nesse lugar. Idealizávamos mostrar o 'real do CAPS', a espontaneidade dos encontros, as singularidades que ali estão, filmar histórias e entrevistas que mostrariam a vida que se expande e escapa desse contexto. Já nas primeiras entrevistas, nos deparamos com essa dificuldade. Existiria um algo de oculto a mostrar?

Percebemos que a câmera e a produção audiovisual modificam de diversas formas o cenário. Às vezes, tornando visíveis modos hegemônicos e permitidos de se falar e, por vezes, modos mais autônomos. A destarte, os integrantes do CAPS ensaiam as falas em casa, para tudo sair perfeito. Ligam para pedir se podem falar de determinadas coisas, enviam seus vídeosensaio, para assistir antes da tão esperada filmagem.

Um dos participantes chega ao serviço vestido com uma roupa social e todo arrumado para ser filmado; outra nos chama para filmá-la no pátio, elas dançam, cantam e se mostram 
para a câmera. Ora, mostrar-se pode ser entendido como uma resistência à invisibilidade, um embate com as forças de opressão e dominação que imperam sobre a loucura (FOUCAULT, 1984) e permitem se expressar por meio do dispositivo-filme (DELEUZE, 1990; BARROS, 1997).

Já uma profissional preferiu não ceder suas imagens e participar apenas por meio de entrevista. Nesta, ela conta de como precisou reaprender a olhar:

Eu tinha uma ideia da doença, do problema em si e é muito mais amplo, é muito maior. São seres humanos com histórias de vida incríveis que são muito mais do que a doença que estão vivendo. Que são pais de alguém, filhos de alguém, esposolesposa de alguém, namorado de alguém. Tem muita vida além da doença (FALA ENTREVISTADA).

Aqui, o filme-dispositivo torna dizível um modo de operar cristalizado, focado na doença; porém, também cria novos regimes de enunciação, que tensionam linhas de força, quando o profissional ressignifica seu fazer, muda o rumo, das intervenções, das palavras e, mesmo que escolha o dizer, torna visível esta relação (DELEUZE, 1990; BARROS, 1997).

Passos, Kastrup e Escóssia (2015) apostam na inseparabilidade do conhecer e fazer. Toda a pesquisa é intervenção, pois produz efeitos sobre o pesquisador, o objeto, os resultados e o próprio processo de pesquisa. Nesse sentido, a produção de um audiovisual como um dispositivo coloca os indivíduos como atores, protagonistas e autores dessa história, retira-os do lugar até então reservado a eles - o de reclusão e invisibilização. Além de intervir nos trabalhadores, ao potencializar o seu fazer cotidiano e lhes permitir significar seu trabalho.

São movimentos interessantes que o audiovisual acompanha. Os profissionais, nesse lugar, sentem-se convidados a pensar suas práticas, significar seu fazer frente à câmera e falar de como pensam a importância do serviço. Uma questão muito presente no espaço de tempo da produção foi justamente a falta de profissionais. A pesquisa não se isenta nesse momento, e várias cenas mostram o dilema vivenciado no serviço.

Durante a produção, pensávamos em como montar esse quebra-cabeças. Quando alguém era filmado, explicávamos que as imagens seriam editadas para serem montadas como um filme e, talvez algumas não seriam usadas. Já na edição, vivenciamos muitos lutos. Cada cena continha um afeto, um momento, mas a primeira produção a surgir era demasiado extensa e passa por diversos ajustes. Além disso, era constante o questionamento sobre a utilidade/efetividade das ações. Estaríamos contribuindo de alguma forma com os sujeitos? Apesar de não poder respondê-los de todo, entendemos esses questionamentos como 
primordiais na pesquisa-intervenção, por ressaltarem um compromisso ético e político com os envolvidos de que as ações não se tornem rasas e sem sentido.

Entre um excesso de imagens e um emaranhado de vídeos, algumas linhas aparecem sutis e insistentes. Ainda não encontramos um caminho, mas observamos várias entradas. Começamos a pensar que esta organização linear, típica do pensamento dito científico, talvez não se faça necessária, quando nos propomos a cartografar movimentos de resistência, de desejos, de afetos. Assim, passamos a pensar o vídeo-documentário enquanto um rizoma.

\section{Linhas rizomáticas}

Quando Deleuze e Guattari (1996) propõem o conceito de rizoma, o próprio texto 'Mil Platôs: Capitalismo e esquizofrenia' se constitui de forma rizomática, pois os princípios ali elencados não são excludentes, e sim complementares. Eles se relacionam entre si e com o todo e podem ser compreendidos em qualquer sequência. Assim percebemos a construção do presente trabalho e do próprio filme, porquanto esse processo não ocorre de forma linear e hierárquica, já que obedecia aos fluxos do instante.

São linhas que acionam o documentário, linhas de visibilidade, de enunciação, de força e de subjetivação (DELEUZE, 1990) e também são linhas (rizomáticas) que lhe dão um sentido e o constroem, permitindo ir de um lado a outro sem um meio. Ao contrário da árvore e da raiz, que nascem em um determinado ponto e se proliferam a partir dele, o rizoma é um sistema acentrado e, por isso, uma linha não se opõe ou sobrepõe à outra. Daí surge seu primeiro princípio, o de conexão e heterogeneidade (DELEUZE E GUATTARI, 1996).

No documentário e na produção escrita, a primeira linha a se desenrolar é a linha da vida, das histórias de cada um enquanto sujeito e sua história com o serviço de saúde mental. A segunda, a do cuidado, fala da relação dos sujeitos com o seu tratamento. A terceira, a da desinstitucionalização, narra a luta pela afirmação de um ser louco que não admite preconceitos e questiona a própria ideia de sanidade.

Quando começamos a roteirizar a montagem do filme/cartografia, tais linhas são visíveis, mas não estáticas; é difícil saber onde uma termina e outra começa. Como separar a vida dos sujeitos de seu sofrimento? Ou, ainda, da sua entrada no CAPS? Como dividir seu tratamento de sua luta por direitos, por reconhecimento?

Não foi fácil abandonar a ordem e a hierarquia. Constituídas e subjetivadas em um mundo e em uma academia que primam pelo enquadre, sofremos por diversas vezes em abrir 
mão da regra e nos permitir ser levadas pelo texto, pelo vídeo que se construía não em sequência, mas em paralelo. Uma frase por dia, uma aqui e outra lá adiante. Um recorte do vídeo, assim como um platô, encaixa-se perfeitamente em vários lugares e de diferentes formas.

O que nos obriga a pular diretamente ao quarto princípio do rizoma, a sua 'ruptura asignificante', na qual um rizoma “pode ser rompido, quebrado em um lugar qualquer, e também retoma segundo uma ou outra de suas linhas e segundo outras linhas" (DELEUZE E GUATTARI, 1996: 18). O filme precisou ser rascunhado, ser desenhado, para, só então, ser construído.

Ainda segundo Deleuze e Guattari (1996), o rizoma diferente do decalque e da fotografia, é um mapa que pode ser construído, desmontado e reconectado, pois possui múltiplas entradas, saídas e linhas de fuga. Como uma antigeneaologia, o rizoma se opõe à reprodução.

Essas conclusões agrupam os dois últimos princípios: o da cartografia e da decalcomania. O papel do pesquisador é, então, conforme Rolnik (2014), o de estar mergulhado nas intensidades e atento às linguagens, para devorar os elementos possíveis para a cartografia. Assim, filmamos um dia alguém no pátio, no outro dia, um depoimento, sem pensar em uma ordem ou roteiro. Vários fragmentos são experimentados, platôs (planos de intensidade), enfim, múltiplos, que não se encaixam em um uno.

Para Rolnik (2014), o cartógrafo é um antropófago, pois devora as coisas encontradas e consideradas como elemento para sua cartografia. Assim, antropofagicamente, selecionamos aquilo que expressa essa cartografia, os desejos por ela mapeados. Em todo o processo, não estamos imunes, pelo contrário, misturadas e afetadas de diversas formas. Por mais que tentássemos uma isenção no momento da filmagem, não aparecer, não questionar, as cartógrafas se fazem presentes em diferentes momentos, através de um riso, de um olhar, de starts oferecidos às narrativas. Ou mesmo através de uma câmera que, em alguns momentos, parece dançante, ofegante e movimenta-se no ritmo dos corpos.

Tomando novamente a ideia da produção audiovisual como um dispositivo estético, pensamos suas linhas: de visibilidade, de enunciação, de força e de subjetivação. Estas se enroscam, fazem nós e amarrações junto às linhas propostas nesse trabalho, a saber, as de vida, de cuidado e de desinstitucionalização. Também no dispositivo, suas linhas passam por todos os lugares em um vai e vem, e podem ser mescladas, o que torna sem sentido distingui-las umas das outras. Ainda assim, procuramos desembaraçar algumas destas, cartograficamente, ao 
marcar as rupturas, enrijecimentos, cruzamentos. Não existem sentidos a serem revelados, mas criados (BARROS, 1997; DELEUZE, 1990).

\section{Linhas de Vida}

Hélio caminha pelo CAPS, como se fosse invisível, sua voz é quase inaudível e, por isso, poucas pessoas se atêm a conversar com ele. Por ser um dos participantes considerados como 'crônicos estáveis', recebe pouca atenção da equipe; afinal, ele 'não incomoda'. Mesmo assim, há uma sutileza em sua existência, algo que atrai estagiários e residentes a se aproximarem dele.

Quando iniciamos as filmagens, é difícil convencê-lo a participar; são diversas tentativas de explicar o trabalho e até a dificuldade de ouvi-lo contribui para a nossa comunicação falhar. Nesse meio tempo, filmamos diversos espaços em que Hélio participa e, assim como no cotidiano do serviço, ele se faz invisível. Porém, todas as vezes que saímos com os equipamentos (câmera, tripé, microfone), é ele quem nos ajuda a carregá-los, posicioná-los, enquadrar as cenas, sugerir lugares com uma maior visibilidade. Por vezes, fica atrás das câmeras e observa o que se filma.

Quando finalmente autoriza o uso de sua imagem, é ele quem nos indaga, questiona e entrevista. Nas imagens, permanece curvado, não olha para a câmera e, mesmo com o microfone ligado, torna-se difícil ouvi-lo. Porém, quando falamos da invisibilização no CAPS, ele concorda com um aceno de cabeça. 


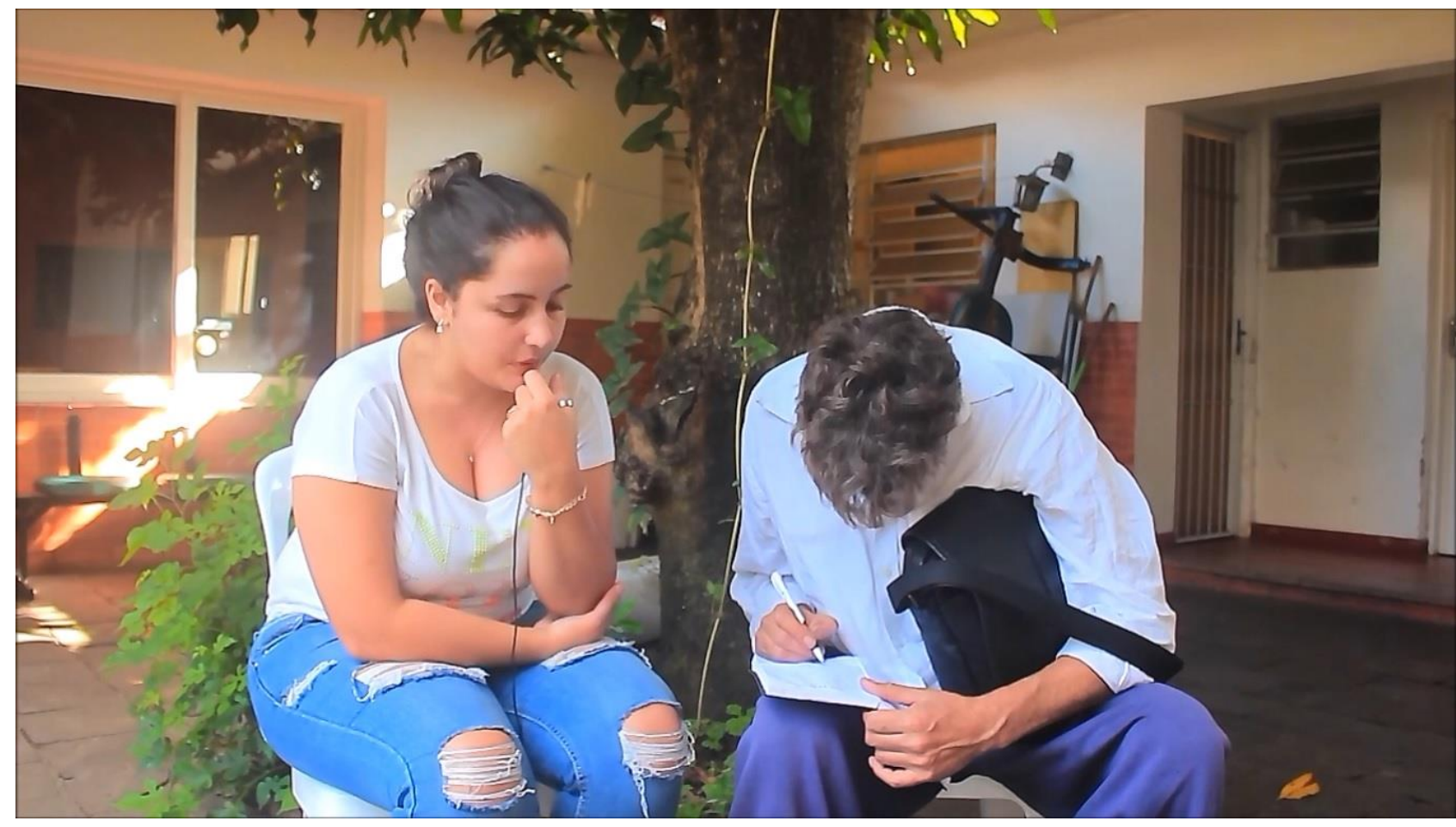

Imagem 5: Imagem retirada da produção audiovisual, onde uma das pesquisadoras é entrevistada por Hélio.

Assim, a produção audiovisual, como um dispositivo (DELEUZE,1990), torna visível e dizível aquilo que é negado em Hélio: sua existência. Através dos seus movimentos de ajudar com as filmagens, e entrevistar, ele sinaliza um sujeito, uma história contada a seu modo. As legendas não apenas facilitam ouvi-lo, mas o inserem nesse espaço do dizível e, se ainda há alguma dúvida sobre essa invisibilidade, um simples gesto seu traz isso à cena.

Por outro lado, Jacinto tem o dom da oratória, fala pausadamente e abre espaços para a reflexão dos ouvintes, como se recitasse um poema quando se comunica. Assim, seu corpo grande e desajeitado se confunde com a delicadeza de suas palavras e a sensibilidade de seus poemas. É ele quem explica e dá o rumo de como será a produção audiovisual: 'Cada um vai contar um pouco da sua história, de como conheceu o CAPS, porque está aqui, qual é o resultado que está tendo...'.

Hélio e Jacinto apresentam o filme e resolvem inverter o processo, ao nos entrevistar. Assim, a primeira linha a se desenrolar, a da vida, narra a história que os participantes do CAPS decidem fazer/contar. Também se expressa nas singularidades, traduzida no jeito de ser/estar 
diferente em cada cena, nas múltiplas formas de falar, se colocar e nas cores que saltam aos olhos.

Não existe uma linearidade nas falas, nem mesmo uma tentativa de construí-la, pois se entende que cada sujeito dá o seu tom em sua forma de se narrar. Os diagnósticos podem ser parecidos, por vezes, são até os mesmos, porém as formas de vivenciá-lo e apresentar a si mesmos são únicas. Estela diz 'minha depressão começou num momento muito bom da minha vida' e é seguida por Clara: 'Eu comecei a participar do CAPS aqui depois que mataram a minha filha, meu próprio companheiro matou ela'.

Sem dúvida, o sofrimento também está presente. Alguns participantes resolvem falar de suas crises, do desejo de suicídio e do fim da vida. Cíntia conta para as colegas como foi a sua última tentativa de suicídio. Na cena, ela aparece, mostrando com as mãos a quantidade de medicamentos que tomou, mas o colorido da imagem nos toma de tal forma, que resolvemos compô-la em música. Prestamos atenção nas cores e são elas que trazem o sofrimento a cantar "Eu ando pelo mundo prestando atenção em cores que eu não sei o nome, cores de Almodóvar, cores de Frida Kahlo" (CALCANHOTO, 1992). Substituímos o áudio pela canção 'Esquadros' e esta tem o poder de suavizar este momento, brincar com o dizível e o visível.

Mesmo pedindo para contarem um pouco de si, os participantes narram-se a partir da entrada no CAPS e dos seus diagnósticos. Entendemos que, como parte constitutiva e integral de cada sujeito, a doença precisa também vir à cena. Eles não se importam de escondê-la, de falar frente às câmeras do seu desejo de morte ou de seu sofrimento.

Para Deleuze (1990), a realidade não é feita de objetos a serem decodificados, não há oculto a ser revelado, o que existe são blocos de invisível a buscar passagem, sendo necessárias incisões para que se tornem visíveis. Pensando nesse emaranhado de linhas das histórias que se cruzam e se diferenciam, nota-se de imediato que falamos de múltiplos, o que a produção audiovisual faz é mapear estas linhas, cindir a fenda que as liga, para que se tornem visíveis. A aproximação é por diferenças e o dispositivo causa a irrupção destes mundos que saem, destas existências-resistências que encontram espaço para se expressar. Assim, contam suas lutas por mais respeito, cuidado, autonomia, sentem-se olhados, visibilizados, encaram a câmera como se encarassem o mundo para lhe dizer de sua existência.

\section{Linhas de cuidado}


O novo modelo de atenção em saúde mental, proposto pela reforma psiquiátrica, trouxe muitas reflexões sobre o cotidiano de trabalho nos CAPS, os modos de atenção, a produção de vida e de autonomia. Porém, para além dessa discussão, pretendemos abordar um olhar do sujeito sobre si, um tanto negligenciado nas práticas cotidianas do CAPS que, por vezes, remetem mais a um controle, uma não inclusão destes como parte importante do seu processo.

Auxiliando-nos nessa discussão, Feuerwerker (2014) fala do trabalho em saúde mental como um território onde é possível a mútua produção ou a muita interdição, dependendo do olhar tido sobre os saberes e desejos das pessoas. Para ela, é importante perceber a vida que vem junto com a queixa. Assim, os participantes do CAPS não devem ser entendidos como sujeitos passivos a aguardar algo do saber técnico, pois já possuem uma bagagem, suas histórias, famílias, religião e tudo isso chega juntamente com eles nos serviços.

Nesse ponto, percebemos que a produção audiovisual pôde dar ênfase a esses modos de atenção, pois não são os técnicos convidados a falar sobre o tratamento no CAPS, e sim os próprios participantes o fazem. Nas falas expressas, percebe-se um empoderamento do seu processo de saúde-doença, além de um posicionamento de como querem ser cuidados: 'eu uso o médico', 'eu escolhi estar no grupo psicoterapêutico' ou 'de vez em quando, eu tiro umas férias (do tratamento)'.

Desse modo, a produção tensiona as linhas de força expressas nas relações de poder, colocando em evidência os movimentos de resistência em relação a cuidados vitimizadores, controladores, além de produzir novas subjetividades, ao colocar os participantes de modo ativo no seu tratamento.

Em uma das cenas, Jacinto diz 'Tenho visto que o calor humano, o afeto é uma das coisas principais para esse negócio de doença mental' e Luzineide complementa: 'A maior parte do tratamento é a pessoa confiar no terapeuta'. São falas que promovem rupturas no discurso homogêneo, colocando-se em um lugar ativo. Eles salientam a importância do afeto, da confiança, do sigilo numa relação terapêutica, ensinam um cuidado.

Essa relação não é de todo igual; por vezes, vemos sujeitos ativos e implicados no tratamento, porém, em outras, ocorre uma dependência do serviço e do cuidado dos técnicos. Uma das entrevistadas se refere ao coordenador do serviço usando o termo 'chefe'. Essas falas também não são negadas. Não há, por parte das pesquisadoras, nenhuma tentativa de mostrar apenas movimentos de fuga, apesar deles serem cartografados; porém as relações de poder e as práticas instituídas também são mapeadas. 
Nesse sentido, Dimenstein (2004: 113) refere que, muitas vezes, a simples implantação dos CAPS não supera o modelo manicomial e, dentro desses espaços, persistem saberes e práticas cronificadoras e segregadoras, que buscam a modelagem, a serialização e homogeneização das subjetividades. Há, então, a necessidade de uma "ética comprometida com a invenção de novos modos de vida", transformando os espaços dos CAPS em lugar de combate à homogeneidade e invisibilidade.

O dispositivo aciona, através de uma bela imagem de uma câmera dançante, um terrível e massificador embate: de um lado, ações do saber/poder com vistas a administrar a vida, capturar desejos, controlar corpos; de outro lado, os movimentos de resistência colocam estes mesmos corpos - sedados e amortecidos pela hipermedicalização - a dançar, cantar, falar e mostrar-se.

Desse modo, as linhas de força presentes no dispositivo tensionam as relações de poder a serviço da conservação da instituição e os mecanismos de resistência/afrontamento mostrados através de um cuidado de si e de rupturas dos lugares já estabelecidos. Movimentos impossíveis de serem capturados a olho nu, que encontram espaço para o visível que o dispositivo promove.

\section{Linhas de desinstitucionalização}

Na composição das cenas, assim como no cotidiano do CAPS, placas como "medicação supervisionada", "desligue o telefone durante o atendimento", "acesso restrito aos funcionários" misturam-se ao colorido das paredes/pessoas e confirmam um paradoxo, um regime de forças reativas e antagônicas ali existentes. 


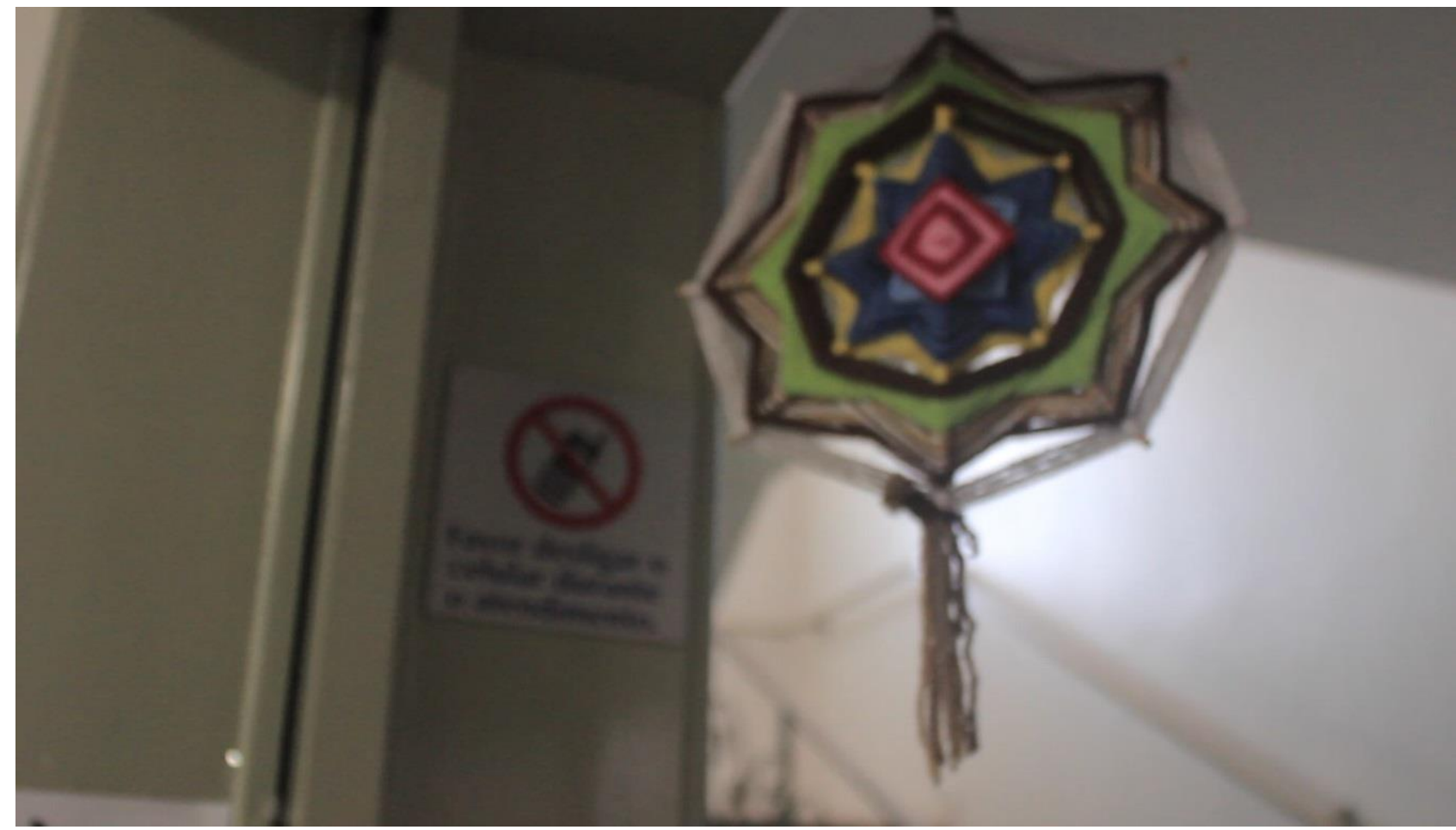

Imagem 6: Imagem retirada da produção audiovisual mostra uma mandala e ao fundo uma placa de proibição.

Novamente, são as linhas presentes no dispositivo que colocam essa relação em evidência. De um lado, forças de combate à homogeneização tentam romper com a lógica manicomial. Por outro, um movimento quase invisível coexiste e se expressa na manutenção de elementos que, historicamente, caracterizam o aparato psiquiátrico, além de evidenciar uma segregação dos loucos e dos técnicos.

Chegamos à terceira linha: a da desinstitucionalização. Palavra que evoca diversos entendimentos, pois comporta não apenas o fim físico de uma instituição, mas também, e sobretudo, os processos instituídos decorrentes dela, nem sempre visíveis, presentes nos discursos, práticas e até mesmo nos sujeitos. Nesse sentido, pode expressar tanto a destituição do manicômio, dos meios de confinamento enquanto estruturas, quanto a derrubada dos mecanismos que agenciavam a existência destes.

Desse modo, Franco Rotelli (2001), um dos principais nomes da reforma psiquiátrica italiana, se propõe a desmistificar o termo. Para ele, o objeto da desinstitucionalização nunca fora apenas o manicômio enquanto estrutura física, com suas violências e usurpações, mas a loucura como doença a ser manejada. A crítica está na divisão feita ao olhá-la como uma coisa 
separada do sujeito, de sua 'existência-sofrimento', de sua relação com o corpo social e a associação com a ideia de periculosidade, que coloca o louco como objeto a ser extinto, se não fisicamente, pelo menos retirado do campo de visão.

A desinstitucionalização buscaria, então, anular a separação entre a doença e a existência global, complexa e concreta do sujeito, ao reconstruir o objeto que as instituições simplificaram. Em outras palavras, a desinstitucionalização busca uma mudança de olhar no qual o foco não é mais a doença, mas o sujeito integral.

Também a pretensão do tratamento deixa de ser a cura, a extinção da doença, para uma emancipação, ressingularização, produção da vida e reprodução social. Isso não implica em negar a existência da loucura enquanto sofrimento, mas poder ler, para além da patologia, a biografia junto dela, desmistificá-la como algo perigoso, a ser temido, afastado (ROTELLI, 2001).

Assim, na produção do documentário, os participantes nos ensinam a desinstitucionalizar, ao botar em xeque a própria ideia de sanidade/loucura. Questionam os serviços, a sociedade e colocam-se como seres integrais. Luzineide se posiciona 'eu tenho pavor de discriminação', ao mesmo tempo que Estela também afirma 'o preconceito oprime'. Mesmo participando do mesmo serviço, ambas nunca se encontraram, porém suas vozes fazem coro quando se trata da desinstitucionalização da loucura. Jacinto também olha fixo para a câmera, para perguntar 'Quem é louco e quem é são?'. Entendemos que questionar a loucura é tirá-la do status de doença para o de modo de existência, pois, mais do que indivíduos loucos, são seres com histórias e singularidades em luta para afirmá-las.

Através das linhas de força e de desinstitucionalização presentes no dispositivo, ocorre um desmantelamento dos muros visíveis e invisíveis e dos lugares fixos nesse CAPS. É necessária a constituição de novas subjetividades, não como algo introspectivo e individual de cada um, mas como novas formas de ser/estar no mundo.

Convocamos, então, o dispositivo em suas linhas de subjetivação, de invenção dos modos de existir propostas por Deleuze (1990). Nesse sentido, o filme possibilita processos de subjetivação e ressignificação dos modos de ser em um CAPS, pois tira os participantes de um lugar de espectadores passivos, para um lugar de potência, autonomia. O dispositivo conecta os sujeitos com o mundo.

Por exemplo, a história de Seu Hortênsio poderia ser definida como um simples diagnóstico de TEPT (transtorno de estresse pós-traumático). Após cair de um prédio, ele passa 
a reviver o trauma em diversos momentos, inclusive quando, em um veículo em movimento, revê as cenas passando rápido como as do prédio de que caíra. Porém, a forma como ele conta essa história já deixa claro o quão singular é sua experiência em relação à própria doença.

Em um dado momento das filmagens, seu Hortênsio diz 'logo eu, que tenho medo de altura, agora estou no ar'. Essa fala nos coloca a pensar no encontro dos participantes com o além do muro do CAPS, com o inesperado que produz visibilidade. Se antes seu Hortênsio viase incapaz e com 'medo de altura', estar 'no ar' o coloca em um lugar de potência, num campo amplo de visão. Não é apenas o seu Hortênsio com medo, frágil e doente, agora ele 'está no ar', nas alturas, conectado com o mundo que o olha.

Rotelli (2001) fala de uma mobilização que a desinstitucionalização promove. Primeiro, os pacientes se apoderam de seus direitos e de sua existência; assim, convidam os técnicos para exercer o seu papel de forma mais libertária possível e, após, eles chamam os setores responsáveis. Exigem mais espaço, respeito e reconhecimento.

Do mesmo modo, ao menos nesta produção audiovisual, os 'muros do CAPS' não substituem os do manicômio, pois não são capazes de aprisioná-los. Esses blocos de concreto e de controle são facilmente transpassados e os sujeitos saem a ocupar outros espaços, como a própria prefeitura da cidade, para exigir que a sua saúde, seu modo de existir seja levado em conta. Exigem melhorias na qualidade do atendimento e dizem que a administração nunca se preocupou com eles. 


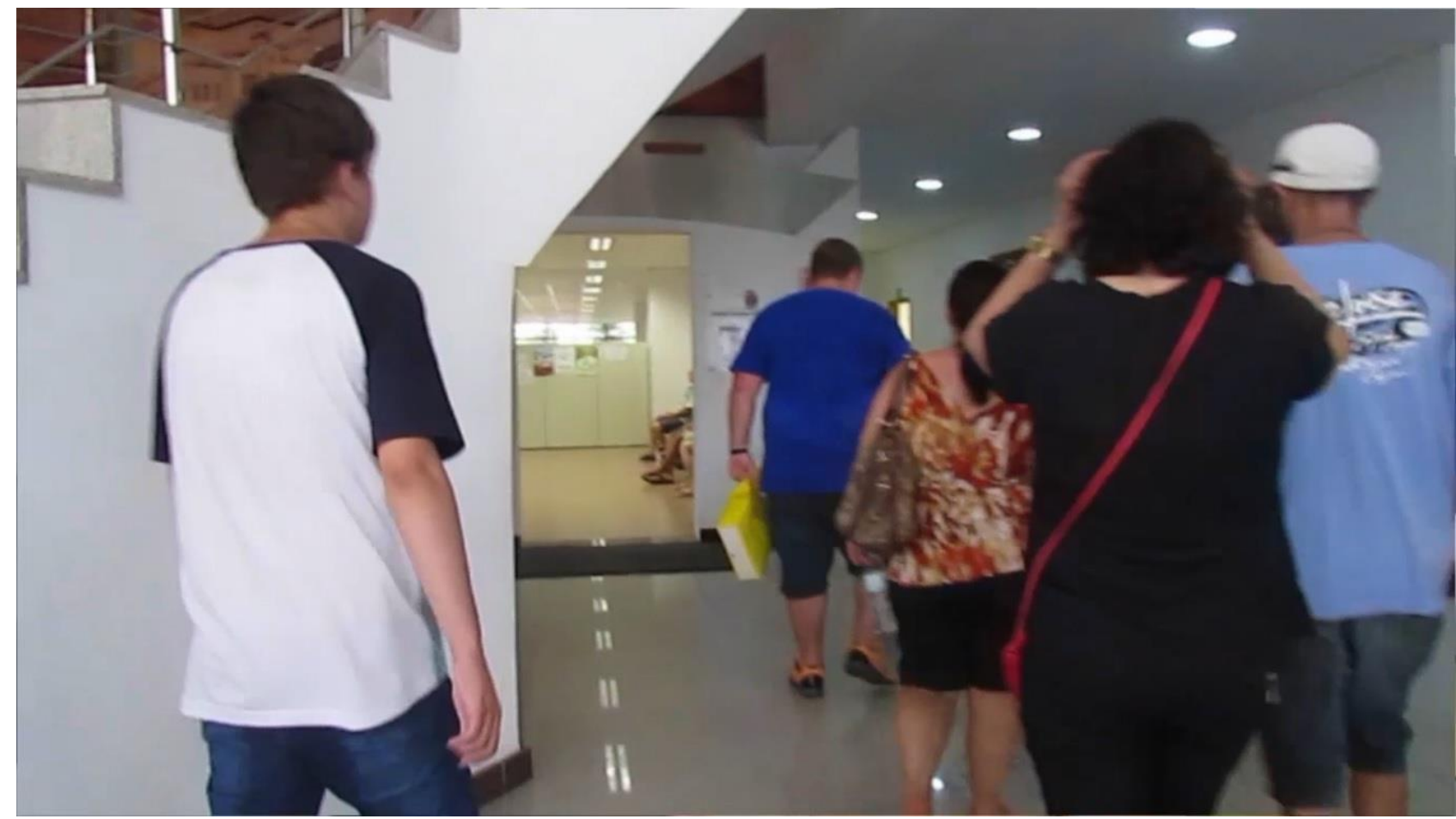

Imagem 7: Imagem retirada da produção audiovisual, onde os usuários estão indo à prefeitura.

Também destituem o lugar do terapeuta e do paciente, ao colocarem-se como participantes do CAPS. A coerência e consistência de suas falas levam os espectadores a questionar: quem são estas pessoas? Seriam elas profissionais a falar sobre um serviço que conhecem? Contudo, a dinâmica do vídeo e o posicionamento ético da cartógrafa não permitiram separar os participantes do CAPS em seu escopo. Portanto, pelo menos nessa produção, os lugares não são fixos; uma vez que se deslocam, não existe uma linha hierárquica a separá-los.

\section{Considerações Finais}

Nesse trabalho, mostramos as inúmeras formas pelas quais a loucura foi e ainda é silenciada, escondida, invisibilizada. Falamos dos espaços de saúde como os CAPS e dos seus habitantes, das inúmeras tentativas de escondê-los e de sufocar seus modos de ser. Sinalizando que, apesar de tantas conquistas em relação ao cuidado em saúde mental - avanços inegáveis se pensarmos o contexto que antes imperava nos manicômios, de abandono, tortura e privações de liberdade, de direitos e de existência -, ainda persistem formas de enclausuramento.

As pesquisadoras procuraram, então, intervir, mexer neste lugar instituído de separação e invisibilização, produzindo um audiovisual que toma os sujeitos como protagonistas e autores dessa história. Assim, traçamos o percurso de volta a esse espaço, retomando questões 
vivenciadas durante o período de estágio; todavia, nesse retorno, muita coisa mudou, tanto no lugar quanto em nós mesmas. Além disso, levamos conosco um poderoso instrumento de guardar momentos, de contar histórias, de revelação: a câmera. Essa tarefa, contudo, trouxe algumas dificuldades; pois como dar visibilidade às relações de poder e aos movimentos de resistência, se estes são invisíveis ao olho da câmera?

Para tanto, na produção do documentário, foi necessário recorrer a outros recursos, para que algo tão amplo pudesse vir à cena. As linhas do dispositivo propostas por Deleuze (1990) são então acionadas em sua função de trazer para o visível e dizível esses mecanismos presentes no CAPS. Também as linhas do rizoma percorrem essa construção, constituindo-as de forma acentrada e não linear, fazendo nós, conexões e emaranhando-se àquelas propostas no trabalho, a saber: as linhas de vida, de cuidado e de desinstitucionalização.

Nesse sentido, o audiovisual torna-se um dispositivo, ao trazer à cena modos de resistência presentes em cada linha que se desenrola, expressos através dos relatos, das histórias de vida, de tratamento e dos movimentos ao longo do filme: as danças, as músicas.

Ademais, para além da questão acadêmica, de produção de dados, foi possível explorar uma relação que se estabeleceu entre as cartógrafas e os sujeitos envolvidos, expressa em um 'fazer junto' em que todos puderam filmar, falar sobre si, entrevistar, entre outras ações.

Ao entender que, por muito tempo, a Psicologia serviu aos ideais de isolar a loucura do olhar, buscamos construir um fazer em Psicologia implicado com a superação destas fronteiras e dos chamados manicômios mentais. Para Romagnoli (2009), essa clínica com vistas a superar a existência de hospitais psiquiátricos em miniatura e a imposição de modos de vida serializados deve ter como objetivo primeiro a produção e potencialização das resistências (ROMAGNOLI, et.al, 2009).

Assim, buscamos uma clínica da resistência e de afirmação de que os modos de vida singulares têm o direito de existir e de ser olhados pelo social. Isso ocorre quando, ao retornar ao CAPS com a câmera em mãos à procura de movimentos de resistência, nos colocamos em outro lugar, em outra relação; já não somos mais tão atravessadas pelas durezas da instituição e passamos a ter um novo olhar sobre o serviço. Um olhar mais suave, apoiado naquilo que encontramos de potência, no que escapa aos enrijecimentos. Diferente de uma visão caricatural, mostramos movimentos, mesmo sutis, de vida, de cuidado e desinstitucionalização. Também os participantes não são mais os mesmos; agora são atores e estrelam em uma superprodução. 


\section{Referências}

AMARANTE, Paulo. Loucos pela vida: a trajetória da reforma psiquiátrica no Brasil. $2^{\mathrm{a}}$ Edição. Rio de Janeiro: Fiocruz, 1995.

BARROS, Regina Benevides de. Dispositivos em ação: o grupo. In: Saúde Loucura: número 6. São Paulo: Editora Hucitec, 1997. p. 183-191.

CALCANHOTTO, Adriana. Esquadros. [1992]. Disponível em:

$<$ https://www.vagalume.com.br/adriana-calcanhoto/esquadros.html>. Acesso em: 11 abril 2017.

DELEUZE, Gilles e GUATTARI, Félix. Mil Platôs: Capitalismo e esquizofrenia. Rio de Janeiro: Editora 34, 1996. Tradução de Aurélio Guerra Neto e Celia Pinto Costa.

DELEUZE, Gilles. ¿Que és un dispositivo? In: Michel Foucault, filósofo. Barcelona: Gedisa, 1990.

FEUERWERKER, Laura Camargo Macruz. Micropolítica e saúde: produção do cuidado, gestão e formação. Porto Alegre: Rede Unida, 2014.

FOUCAULT, Michel. Deux essais sur le sujet et le pouvoir. In: Michel Foucault: Un parcours philosophique. Paris: Gallimard, 1984, p. 297-321. Disponível em: <http://jornalista.tripod.com/teoriapolitica/3.htm>

FOUCAULT, Michel. História da loucura na idade clássica. São Paulo: Perspectiva, 1997.

PASSOS, Eduardo; KASTRUP, Virgínia; ESCÓSSIA, Liliana da (Org). Pistas do método da cartografia: Pesquisa-intervenção e produção de subjetividade. Porto Alegre: Sulina, 2015 .

PELBART, Peter Pál. Manicômio Mental. In: A nau do tempo-rei: sete ensaios sobre o tempo da loucura. Rio de Janeiro: Imago Ed., 1993.

RESENDE, Heitor. Política de saúde mental no Brasil: uma visão histórica. In: Cidadania e

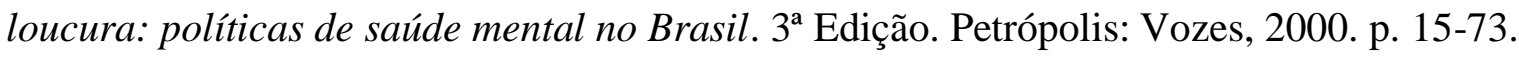

ROLNIK, Suely. Cartografia Sentimental: Transformações contemporâneas do desejo. $2^{\mathrm{a}}$ Edição. Porto Alegre: Sulina, 2014.

ROMAGNOLI, Roberta Carvalho; PAULON, Simone Mainieri; AMORIM, Ana Karenina de Melo Arraes; DIMENSTEIN, Magda. Por uma clínica da resistência: experimentações desinstitucionalizantes em tempos de biopolítica. Revista Interface, comunicação, saúde, educação Botucatu-SP, vol. 6, n. 30, p. 199-207, 2009.

ROTELLI, Franco; LEONARDIS, Ota de; MAURI, Diana. Desinstitucionalização. $2^{\text {a }}$ Edição. São Paulo: Editora Hucitec, 2001.4

Dalmara Fabro de Oliveira

Graduação em Psicologia pela Universidade do Vale do Rio dos Sinos (UNISINOS). Graduação em Teologia pela Universidade Filadélfia (UNIFIL). Mestrado em Saúde Coletiva pela UNISINOS. Psicóloga no Município de André da Rocha/ RS e Conselheira na atual Gestão do Conselho Regional de Psicologia do Rio Grande do Sul (2019 - 2022). E-mail: dalmarafo@edu.unisinos.br 


\begin{abstract}
Vilene Moehlecke
Graduação em Psicologia pela Universidade do Vale do Rio dos Sinos (UNISINOS). Professora do Curso de Psicologia da UNISINOS. Pós-doutorado em andamento em Psicologia Social e Institucional pela Universidade Federal do Rio Grande do Sul (UFRGS). Doutorado em Informática na Educação, PGIE/UFRGS. Mestrado em Psicologia Social e Institucional pela UFRGS e Mestrado Sanduíche em Filosofia pela Universidade Nova de Lisboa. E-mail: vilenemo@unisinos.br
\end{abstract}

1 O trabalho em questão respeitou todos os procedimentos éticos de pesquisa com seres humanos, sendo autorizado pelo Comitê de Ética em Pesquisa (Número do Parecer: 1.874.183). Os participantes foram amplamente informados e assinaram ao Termo de Consentimento Livre e Esclarecido (TCLE) e a declaração de cessão de uso de imagem. Por opção das pesquisadoras, o nome e o local do serviço não serão identificados.

dos dados

2 Os nomes reais dos participantes foram substituídos por nomes fictícios devido à confidencialidade 